\title{
ENHANCEMENT OF ION BEAM CHARGE STATES BY ELECTRON VORTICES IN A PLASMA OPTICAL DEVICE
}

\author{
A. Goncharov ${ }^{1}$, V. Maslov ${ }^{2}$ and I. Brown ${ }^{3}$ \\ ${ }^{1}$ Institute of Physics NASU, Kiev 252650, Ukraine; \\ ${ }^{2}$ NSC Kharkov Institute of Physics and Technology, Kharkov 61108, Ukraine, \\ E-mail:vmaslov@kipt.kharkov.ua; \\ ${ }^{3}$ Lawrence Berkeley National Laboratory, Berkeley, California 94720, USA
}

We consider the possibility of enhancing the ionization charge states of beam ions by electron vortices excited in cylindrically symmetric plasma optical systems of finite length with crossed radial electric and longitudinal magnetic fields. PACS: 52.27.LW

\section{INTRODUCTION}

Electron vortex structures can be excited in cylindrically symmetric systems of finite length with crossed radial electric and longitudinal magnetic fields. In this paper, we consider the possibility of enhancing the ionization charge states of beam ions by such electron vortices. We show that the electron velocity in the vortices can be sufficiently large to increase the ionization charge states of beam ions.

The cylindrical configuration that we consider here makes use of a number of ring electrodes along which an electric potential is distributed. We show that maximum ionization is achieved for minimum ion beam velocity through the vortex region. Though electron-ion collisions provide ionization, they also result in electron transport, in turn leading to reduced electron density. Increased magnetic field results in improved electron confinement. However, for large magnetic field the electron distribution is laminar, resulting in reduced ionization. For a given value of magnetic field, a specific number of discrete electrodes are required, along which the externally applied electric potential is distributed, or (alternatively) for a given number of the electrodes the maximum ionization is reached at a certain magnetic field.

The experimentally observed dependence of electron density $n_{e}$ on magnetic field $H_{o}$ has been analytically investigated. For $\mathrm{H}_{\mathrm{o}}$ less than the optimum magnetic field $\mathrm{H}_{\text {opt }}$ the electron density increases with $\mathrm{H}_{\mathrm{o}}$; for $\mathrm{H}_{\mathrm{o}}$ somewhat greater than $\mathrm{H}_{\mathrm{opt}}, \mathrm{n}_{\mathrm{e}}$ falls with increasing $\mathrm{H}_{\mathrm{o}}$; and for $\mathrm{H}_{\mathrm{o}}$ much greater than $\mathrm{H}_{\mathrm{opt}}, \mathrm{n}_{\mathrm{e}}$ increases with $\mathrm{H}_{\mathrm{o}}$ increasing.

We consider the possibility of increasing the ionization charge states of beam ions by electron vortices self consistently excited in the plasma-optical system. The intensity of the excited vortex turbulence is proportional to magnetic field $\mathrm{H}_{0}$, and the confinement of electrons is improved with increased $\mathrm{H}_{0}$; thus the system calls for large $\mathrm{H}_{0}$. It is necessary to use a certain minimum number of cylindrical electrodes, along which the electric potential is distributed, so that the radial distribution of electrons is not layered.

A plasma-optical system for increasing the ionization state of ions from charge state $n$ up to $n+1$ by electron vortices is considered. The system consists of three cylindrically symmetric segments located axially in the longitudinal direction (see Fig. 1). The configuration is of finite length located in the field of a chain of short coils, the sense of which is such as to create opposing magnetic fields $\mathrm{H}_{0}$, and the separate segments trap electrons.

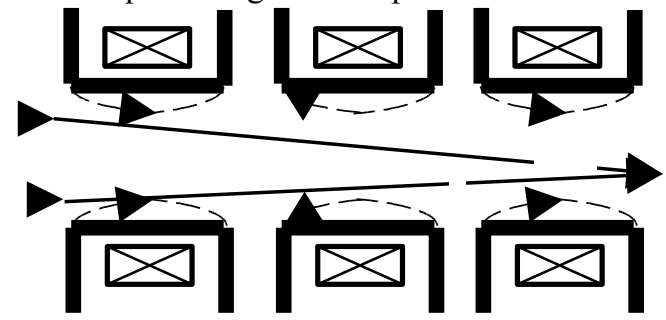

Fig. 1. Schematic of system for increasing ion charge states

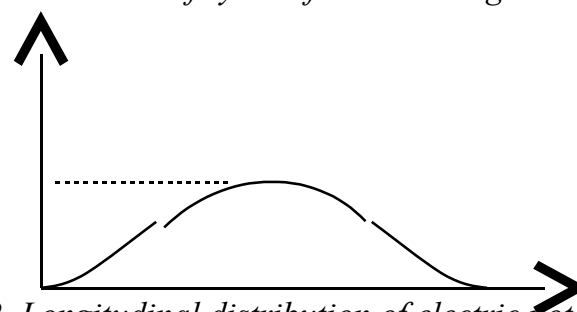

Fig. 2. Longitudinal distribution of electric potential along each segment

Cylindrical electrodes are also positioned axially, along which an electric potential $\Phi_{\mathrm{o}}$ is distributed (see Fig. 2). In each segment the electrons are trapped by $\mathrm{H}_{\mathrm{o}}$ and $\Phi_{\mathrm{o}}$.

The magnetic field structure and the electric potential distribution due to the ring electrodes along each segment are shown qualitatively in Fig. 3.

Fig. 3. Magnetic field structure and electric potential distribution of ring elegtrodes along one segment of the system

The system is filed with flectrons by secondary/ electron emission frop ion bombardment of the cylindrical electrodes by peripheral hram ions. In fach trap volume, ckossed electric and 1 H c fiełs are formed. Such a system is unstaple a leads to

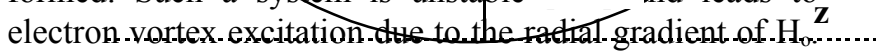
The interaction of beam ions with vortices can result in 
enhanced ionization of transiting beam ions. In Fig. 4 a schematic of the concept with vortex electron trajectories is shown.

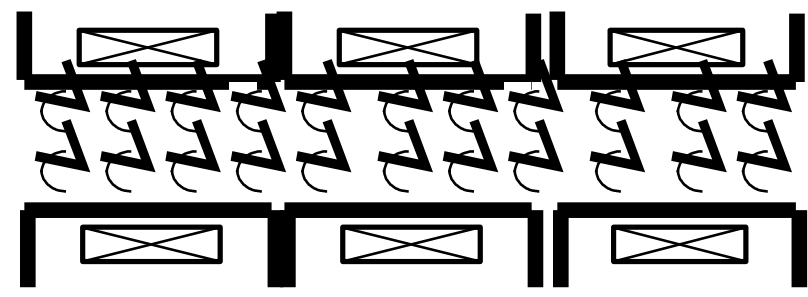

Fig. 4. Excitation of electron vortices

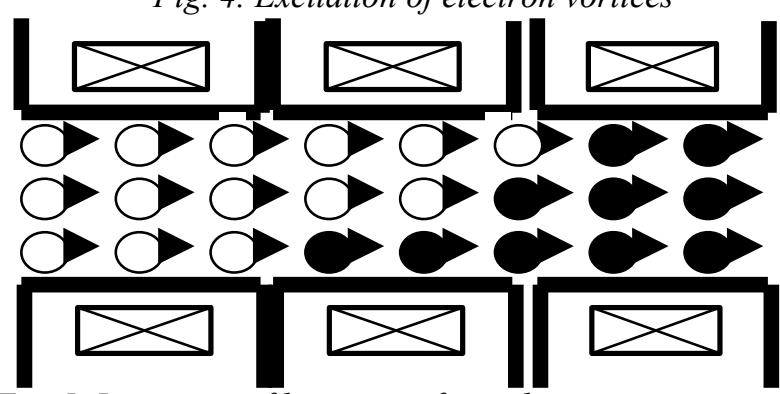

Fig. 5. Ionization of beam ions from charge state $n$ (shown by light circles) up to charge state $n+1$ (shown by dark circles) by electron vortices

The electrons can rotate around the axes of the vortices with significant super-thermal velocities. In Fig. 5 the ionization of beam ions from charge state $n$ (ions shown by light circles) up to charge state $n+1$ (ions shown by dark circles) by electron vortices is shown schematically.

\section{DEPENDENCE OF RADIAL ELECTRIC FIELD ON MAGNETIC FIELD}

Let us consider the dependence of the radial electric field that can be supported in the system on $\mathrm{H}_{0}$. We consider radial collisional electron transport (the continuous curve in Fig. 6, for $\mathrm{H}_{\mathrm{o}}$ less than the optimum, $\mathrm{H}_{\mathrm{o}}<\mathrm{H}_{\mathrm{opt}}$ ) and anomalous electron transport (the continuous curve in Fig. 6 for $\mathrm{H}_{0}$ much greater, $\mathrm{H}_{\mathrm{o}}>>\mathrm{H}_{\mathrm{opt}}$ ). By $\mathrm{H}_{\mathrm{opt}}$ we mean that derived in $[4,5]$, for which vortices are not excited in the system.

We use the fact that the electron density is inversely proportional to the radial electron velocity $n_{e} \sim 1 / V_{r}$. In the collisional case the radial electron velocity is given by $\mathrm{V}_{\mathrm{r}}$ $\approx \mathrm{eE}_{\mathrm{or}} v / \mathrm{m}_{\mathrm{e}} \omega_{\text {ce }}^{2}$, where $v$ is the electron collision frequency, $E_{o r}$ is the radial electrical field, and $\omega_{c e}$ is the electron cyclotron frequency. From this expression and using that at $\mathrm{H}_{\mathrm{opt}}$ the electron density equals $\mathrm{n}_{\mathrm{opt}}$, we find the electron density for $\mathrm{H}_{\mathrm{o}}<\mathrm{H}_{\mathrm{opt}}$,

$$
\mathrm{n}_{\mathrm{e}}=\mathrm{n}_{\mathrm{i}} / 2+\left[\mathrm{n}_{\mathrm{i}}^{2} / 4+\mathrm{n}_{\mathrm{opt}}\left(\mathrm{n}_{\mathrm{opt}}-\mathrm{n}_{\mathrm{i}}\right) \mathrm{H}_{\mathrm{o}} / \mathrm{H}_{\mathrm{opt}}\right]^{1 / 2}
$$

One can see that $\mathrm{n}_{\mathrm{e}}=\mathrm{n}_{\mathrm{opt}}$ at $\mathrm{H}_{\mathrm{o}}=\mathrm{H}_{\mathrm{opt}}$, and $\mathrm{n}_{\mathrm{e}}$ increases with increasing $\mathrm{H}_{\mathrm{o}}$ for $\mathrm{H}_{\mathrm{o}}<\mathrm{H}_{\text {opt }}$.

Upon excitation of turbulence, the radial electron transport increases sharply. The saturation amplitude of the excited vortices is determined by their dissipation rate. Hence the radial transport velocity $V_{r}$ is approximately proportional to the growth rate $\gamma$ of the instability, i.e. to the intensity of vortex excitation. For parameters close to the optimum, slow vortices are excited and $\gamma$ is determined by their growth rate $\gamma_{\mathrm{sl}}$. We have approximately

$$
\mathrm{n}_{\mathrm{e}} \sim 1 / \mathrm{V}_{\mathrm{r}} \sim 1 / \gamma_{\mathrm{sl}} \sim\left[\ell_{\theta} \Delta \mathrm{n} / \mathrm{H}_{\mathrm{o}}\right]^{-1 / 3},
$$

$$
\ell_{\theta} \sim\left[(1-\eta)\left(\partial_{\mathrm{r}}\left(1 / \omega_{\mathrm{ce}}\right) / \mathrm{V}_{\mathrm{o} \theta}\right]^{1 / 2}, \quad \mathrm{~V}_{\mathrm{o} \theta} \sim \Delta \mathrm{n} / \mathrm{H}_{\mathrm{o}} .\right.
$$

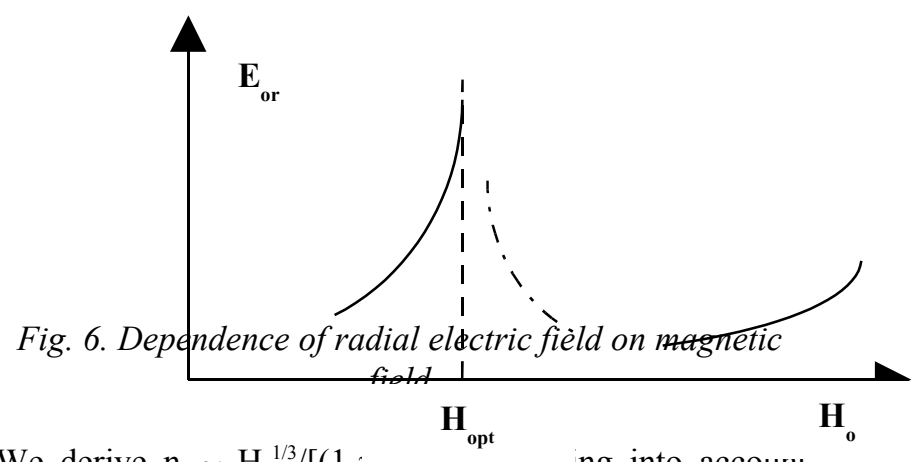

We derive $\mathrm{n}_{\mathrm{e}} \sim \mathrm{H}_{\mathrm{o}}{ }^{1 / 3} /\left[\left(1-1 / \mu_{\mathrm{e}} \Delta \mathbf{H I}\right]\right.$. I aning into accoum that $\mathrm{H}=\eta_{\mathrm{opt}}\left(\Delta \mathrm{n} / \Delta \mathrm{n}_{\mathrm{opt}}\right)\left(\mathrm{H}_{\mathrm{opt}} / \mathrm{H}_{\mathrm{o}}\right)^{2}, \eta_{\mathrm{opt}}=1 . \Delta \mathrm{n} \equiv \mathrm{n}_{\mathrm{oe}}-\mathrm{n}_{\mathrm{oi}}$ is the overcompensation of flow ions by the electrons, we have

$$
\mathrm{n}_{\mathrm{e}} \sim \mathrm{H}_{\mathrm{o}}^{1 / 3} /\left\{\mathrm{n}_{\mathrm{e}} \Delta \mathrm{n}\left[1-\left(\Delta \mathrm{n} / \Delta \mathrm{n}_{\text {opt }}\right)\left(\mathrm{H}_{\mathrm{opt}} / \mathrm{H}_{\mathrm{o}}\right)^{2}\right]\right\}^{1 / 6}
$$

It can be seen that when $\mathrm{H}_{\mathrm{o}}$ exceeds $\mathrm{H}_{\mathrm{opt}}, \mathrm{n}_{\mathrm{e}}$ decreases (the dash-dot curve in Fig. 6).

For $\mathrm{H}_{\mathrm{o}}>>\mathrm{H}_{\mathrm{opt}}$, when the saturation amplitude of the excited turbulence does not strongly depend on $\mathrm{H}_{\mathrm{o}}$, one can introduce an effective electron collision frequency $v_{\mathrm{ef}}$. Then the velocity of radial motion of the electrons equals $\mathrm{eE}_{\text {or }} v_{\text {эфф }} / \mathrm{m}_{\mathrm{e}} \omega_{\text {се }}^{2}$. Thus we find that $\mathrm{n}_{\mathrm{e}}-\mathrm{n}_{\mathrm{i}} \sim \mathrm{H}_{\mathrm{o}}$.

\section{MAXIMUM ENERGY OF ELECTRON ROTATION IN A VORTEX}

Let us estimate the velocity, $\delta \mathrm{V}_{\mathrm{e}}$, of electron rotation in a vortex and compare it with the electron drift velocity, $\mathrm{V}_{\theta}$ ${ }_{\mathrm{o}}=-\left(\mathrm{e} / \mathrm{m} \omega_{\mathrm{He}}\right)\left[\mathbf{e}_{\mathrm{z}}, \mathbf{E}_{\mathrm{ro}}\right]$, in crossed $\mathrm{E}_{\mathrm{ro}}$ and $\mathbf{H}_{\mathrm{o}}$ fields.

One can show [6] that the maximum saturation amplitude of electric potential in a vortex, $\phi_{\mathrm{sm}}$, is

$$
\phi_{\mathrm{sm}} \approx\left(\mathrm{m}_{\mathrm{e}} / \mathrm{ek}^{2}\right)\left[\omega_{\mathrm{He}}^{2} / 2-\left(\Delta \mathrm{n} / \mathrm{n}_{\mathrm{oe}}\right) \omega_{\mathrm{pe}}^{2}\right]
$$

where $\mathrm{k}$ is the wave vector of the vortex perturbation. From it an approximate expression follows for the longitudinal component of rotation of the electron velocity, which characterizes angular speed $\Omega \equiv \mathrm{V}_{\theta} / \mathrm{r}$ of their rotation in the vortex field, $\alpha \equiv \mathbf{e}_{\mathrm{z}} \operatorname{rot} \mathbf{V} \approx\left(\omega_{\mathrm{pe}}^{2} / \omega_{\mathrm{He}}\right) \delta$ $\mathrm{n}_{\mathrm{e}} / \mathrm{n}_{\mathrm{eo}} \approx \omega_{\mathrm{He}} / 2$. Now taking into account that the vortex perturbations are unstable and are excited initially with small azimuth numbers, $l_{\theta}$, the radius of a vortex approximately equals half the system radius, $R_{v} \approx R / 4$. We find the following approximate expression for $\delta \mathrm{V}_{\mathrm{e}}$

$$
\delta \mathrm{V}_{\mathrm{e}} / \mathrm{V}_{\theta_{\mathrm{o}}} \approx \mathrm{R} \omega_{\mathrm{He}} / 4 \mathrm{~V}_{\theta_{\mathrm{o}}} \approx\left(\omega_{\mathrm{He}} / \omega_{\mathrm{pe}}\right)^{2}\left(\mathrm{n}_{\mathrm{oe}} / \Delta \mathrm{n}\right)>>1 \text {. }
$$

From the previous ratio we find that the maximum electron energy due to rotation in the vortex is $\varepsilon_{\mathrm{e}} \approx \mathrm{m}_{\mathrm{e}} \mathrm{R}^{2} \omega$ ${ }_{\mathrm{He}}^{2} / 32$. For experimental parameters such as $\mathrm{R}=3.5 \mathrm{~cm}$, $\mathrm{H}_{\mathrm{o}}=1000 \mathrm{Oe}$, one obtains that $\varepsilon_{\mathrm{e}} \approx 62.5 \mathrm{keV}$. But due to magnetic field inhomogeneity $\varepsilon_{\mathrm{e}}$ is limited by $\Phi_{\mathrm{o}}$. 


\section{INCREASING THE ION FLOW RESIDENCE TIME IN THE SYSTEM}

If we use a plateau-type longitudinal distribution of potential, it is possible to increase considerably the ion residence time in the system. Then the ion beam velocity in the system equals $\mathrm{V}_{\mathrm{bi}}=\left[\left(2 / \mathrm{m}_{\mathrm{i}}\right)\left(\varepsilon_{\mathrm{i}}-\mathrm{e} \Phi_{\mathrm{o}}\right)\right]^{1 / 2}$. If the ion beam energy is only slightly greater than this, $\varepsilon_{\mathrm{I}} \geq \mathrm{e} \Phi_{\mathrm{o}}$, then the beam ion transit velocity in the system will be decreased and the residence time increased.

\section{SYSTEM LENGTH REQUIRED FOR COMPLETE IONIZATION OF FLOW IONS TO CHARGE STATE $n+1$}

Let us estimate the minimum length of the system, L, for which, during the ion beam propagation with velocity $\mathrm{V}_{\mathrm{bi}}$ through the system, $\tau_{\text {пр }}=\mathrm{L} / \mathrm{V}_{\mathrm{bi}}$, there will be complete ionization of beam ions from charge state $n$ up to charge state $n+1$. The time required for additional ionization is given by $\tau_{\mathrm{I}}=1 / \mathrm{n}_{\mathrm{i}} \sigma \mathrm{V}_{\mathrm{e}}$. The ion beam velocity should exceed $\mathrm{V}_{\mathrm{bi}} \geq\left(2 \mathrm{e} \Phi_{\mathrm{o}} / \mathrm{m}_{\mathrm{i}}\right)^{1 / 2}$ for the ion beam propagation through the system. We choose for the best additional ionization, $\mathrm{V}_{\mathrm{bi}} \dot{i}\left(2 \mathrm{e} \Phi_{\mathrm{o}} / \mathrm{m}_{\mathrm{i}}\right)^{1 / 2}$. Then the ion residence time in the system is the longest.

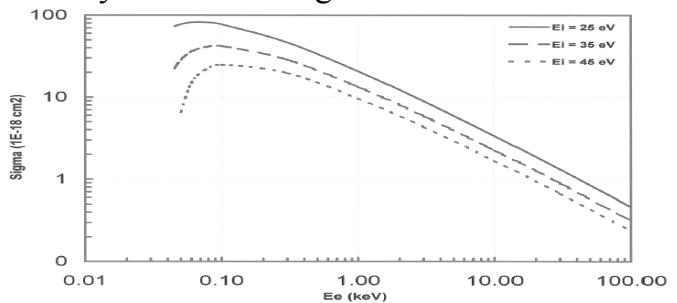

Fig. 7. Dependence of ionization cross section from $T_{a}{ }^{2+}$ to $T_{a}^{3+}$ on electron energy

For complete ionization to charge state $n+1$ the system length $L$ should be greater than $L \geq V_{b i} / V_{e} n_{i} \sigma$. Estimations show that a very long system is necessary for significant ionization. Therefore we use, instead of an ion beam, a vacuum-arc plasma flow. In this case there is no necessity for secondary ion-electron emission, and electrons are moved with the ion flow. The energy of the streaming ions is $100 \mathrm{eV}$. For vortex excitation we use LF wave pumping of frequency approximately equal to the ion plasma frequency, similar to HF wave pumping on electron cyclotron frequency in [7].
To determine L, $\sigma$ has been calculated (see Fig. 7) using an expression given in [8]. Using $\mathrm{n}_{\mathrm{i}}=10^{12} \mathrm{~cm}^{-3}$ and $\sigma$ $=0.82 \times 10^{-16} \mathrm{~cm}^{2}$ for ionization from $\mathrm{T}_{\mathrm{a}}{ }^{2+}$ to $\mathrm{T}_{\mathrm{a}}{ }^{3+}$ we find that if the amplitude of the vortex electric potential is limited to $\Phi_{\mathrm{o}}$, L should be longer than $\mathrm{L}>26 \mathrm{~cm}$.

\section{CONCLUSION}

We have shown that because the magnitude of the excited vortex perturbation is significantly greater than the electron cyclotron radius and because the excited fields of the vortex perturbations are significantly greater than the radial electrical field of the system, the electron vortex velocity can considerably exceed the electron drift velocity in crossed electric and magnetic fields. This results in the possibility of additional ionization of ions. These vortices can be enhanced by LF wave pumping at a frequency approximately equal to the ion plasma frequency.

\section{REFERENCES}

1. A. Goncharov, A. Dobrovolskiy, A. Zatuagan, and I. Protsenko. High current plasma lens.// IEEE Trans. Plasma Sci. (21). 1993, № 5, pp. 573-577.

2. A.A.Goncharov, A.Dobrovolskiy et al. // Plasma Phys. Rep. (20). 1994, № 5, P. 499.

3. A.A. Goncharov, S.N. Gubarev, V.I. Maslov, I.N. Onishchenko. Problems of Atomic Science and Technology, Kharkov, 2001. № 3. P. 1524.

4. A.A. Goncharov, S.M. Gubarev, I.M. Protsenko, I. Brown // Problems of Atomic Science and Technology. (6). 2000, p.124

5. A.A. Goncharov, V.I. Maslov, I.N. Onishchenko// Problems of Atomic Science and Technology. Ser: "Plasma Physics" (7). 2002, № 4, P. 152.

6. A.A. Goncharov, V.I. Maslov, I.N. Onishchenko// Plasma Phys. Rep. (30). 2004, № 7. P. 1.

7. See, for instance, D. Leitner and C. Lyneis. ECR Ion Sources./edited by I.G. Brown// Physics and Technology of Ion Sources. Vol. 2, Wiley-VCH, Berlin, 2004.

8. A.Muller, E.Salzborn, R.Frodl, R.Becker, H.Klein, H.Winter.// J.Phys. B. Atom. Molec. Phys. (13). 1980, P. 1877-1899.

\section{ДОИОНИЗАЦИЯ ИОННОГО ПУЧКА ЭЛЕКТРОННЫМИ ВИХРЯМИ В ПЛАЗМО-ОПТИЧЕСКОЙ СИСТЕМЕ}

\section{А.А. Гончаров, В.И. Маслов, Я. Браун}

Рассматривается возможность доионизации ионов пучка электронными вихрями, возбуждаемыми в цилиндрически симметричной плазмо-оптической системе конечной длины со скрещенной конфигурацией радиального электрического и продольного магнитного полей.

\section{ДОІОНИЗАЦІЯ ІОННОГО ПУЧКА ЕЛЕКТРОННИМИ ВИХОРАМИ В ПЛАЗМО-ОПТИЧНІЙ СИСТЕМІ}

\section{О.А. Гончаров, В.І. Маслов, Я. Браун}

Розглядається можливість доіонизації іонів пучка електронними вихорами, що збуджуються в циліндрично симетричній плазмо-оптичній системі кінцевої довжини зі схрещеною конфігурацією радіального електричного і повздовжнього магнітного полів. 